\title{
Improving eukaryotic genome annotation using single molecule mRNA sequencing
}

Vincent Magrini ${ }^{1 \dagger}$, Xin Gao ${ }^{1 \dagger}$, Bruce A. Rosa ${ }^{1 \dagger}$, Sean McGrath ${ }^{1}$, Xu Zhang ${ }^{1}$, Kymberlie Hallsworth-Pepin ${ }^{1}$, John Martin ${ }^{1}$, John Hawdon², Richard K. Wilson ${ }^{1,3}$ and Makedonka Mitreva ${ }^{1,3^{*}}$

\begin{abstract}
Background: The advantages of Pacific Biosciences (PacBio) single-molecule real-time (SMRT) technology include long reads, low systematic bias, and high consensus read accuracy. Here we use these attributes to improve on the genome annotation of the parasitic hookworm Ancylostoma ceylanicum using PacBio RNA-Seq.

Results: We sequenced 192,888 circular consensus sequences (CCS) derived from cDNAs generated using the CloneTech SMARTer system. These SMARTer-SMRT libraries were normalized and size-selected providing a robust population of expressed structural genes for subsequent genome annotation. We demonstrate PacBio mRNA sequences based genome annotation improvement, compared to genome annotation using conventional sequencing-by-synthesis alone, by identifying 1609 (9.2\%) new genes, extended the length of 3965 (26.7\%) genes and increased the total genomic exon length by $1.9 \mathrm{Mb}$ (12.4\%). Non-coding sequence representation (primarily from UTRs based on dT reverse transcription priming) was particularly improved, increasing in total length by fifteen-fold, by increasing both the length and number of UTR exons. In addition, the UTR data provided by these CCS allowed for the identification of a novel SL2 splice leader sequence for $A$. ceylanicum and an increase in the number and proportion of functionally annotated genes. RNA-seq data also confirmed some of the newly annotated genes and gene features.
\end{abstract}

Conclusion: Overall, PacBio data has supported a significant improvement in gene annotation in this genome, and is an appealing alternative or complementary technique for genome annotation to the other transcript sequencing technologies.

Keywords: Genome annotation improvement, Pacific bioscience mRNA sequencing, Ancylostoma ceylanicum, Hookworm, Gene loci

\section{Background}

Compared to conventional 454/Roche and/or Illumina sequencing platforms, the Pacific Biosciences's (PacBio) much longer reads and improved accuracy using circular consensus sequences (CCS) are advantageous for sequencing cDNA libraries because i) each library read is from a single transcript molecule, ii) mRNA CCS lengths on PacBio easily exceed $1 \mathrm{kbp}$, iii) the longer reads provide a unique opportunity to identify $5^{\prime}$ and $3^{\prime}$ boundaries or untranslated regions (UTRs), and iv) for each gene,

\footnotetext{
* Correspondence: mmitreva@wustl.edu

${ }^{\dagger}$ Equal contributors

${ }^{1}$ McDonnell Genome Institute, Washington University School of Medicine, St. Louis, MO 63108, USA

${ }^{3}$ Department of Medicine, Washington University School of Medicine, St. Louis, MO 63110, USA

Full list of author information is available at the end of the article
}

multiple transcripts may exist and long read sequencing provides exon-exon boundaries that discriminate isoforms and novel fusions. In contrast to short read technologies, the disadvantage of obtaining a reduced dynamic range of gene expression is irrelevant when the goal is accurate gene annotation.

To understand genome organization and genic content, whole genome shotgun approaches have been traditionally assembled from short read NGS technologies such as the 454/Roche and/or Illumina platform for many organisms including nematodes [1-3]. The quality of the published draft assemblies is variable (Table 1; e.g. $[1,3]$; Accession numbers of all published nematode genomes are available on Nematode.net) and may result in suboptimal downstream comparative genomic analysis including gene annotation. Thus, examining approaches that use other technologies (such as the long read 
Table 1 Comparison of genome statistics to other nematode species

\begin{tabular}{|c|c|c|c|c|c|c|c|c|c|c|c|c|}
\hline \multirow[t]{2}{*}{ Species } & \multirow{2}{*}{$\begin{array}{l}\text { Phylo } \\
\text { genetic } \\
\text { clade }\end{array}$} & \multirow{2}{*}{$\begin{array}{l}\# \\
\text { Genes }\end{array}$} & \multirow{2}{*}{$\begin{array}{l}\text { CEGMA } \\
\text { completeness }\end{array}$} & \multirow{2}{*}{$\begin{array}{l}\text { Average } \\
\text { gene } \\
\text { length }\end{array}$} & \multirow{2}{*}{$\begin{array}{l}\text { Assembly } \\
\text { Length } \\
\text { (bp) }\end{array}$} & \multirow{2}{*}{$\begin{array}{l}\# \\
\text { Scaffolds }\end{array}$} & \multicolumn{2}{|l|}{ N50 } & \multirow{2}{*}{$\begin{array}{l}\text { GC } \\
\text { content } \\
\%\end{array}$} & \multicolumn{3}{|c|}{ Contig Length } \\
\hline & & & & & & & $\#$ & Length & & Mean & Median & $\begin{array}{l}\text { Max } \\
\text { Length }\end{array}$ \\
\hline Trichinella spiralis & I & 16,380 & $95.6 \%$ & 952.8 & $63,525,422$ & 6863 & 4 & $6,373,445$ & 33.9 & 9256 & 1071 & $12,041,450$ \\
\hline Trichuris muris & । & 11,004 & $96.1 \%$ & 1245.7 & $84,674,602$ & 1683 & 59 & 400,602 & 44.8 & 50,312 & 1914 & $1,774,400$ \\
\hline Trichuris trichiura & । & 8813 & $96.1 \%$ & 1293.9 & $75,496,503$ & 4156 & 265 & 70,602 & 42.2 & 18,166 & 3965 & 533,758 \\
\hline Ascaris suum & III & 15,260 & $98.9 \%$ & 1188.5 & $265,545,801$ & 31,538 & 260 & 290,558 & 37.8 & 8420 & 226 & $1,465,500$ \\
\hline Brugia malayi & III & 18,074 & $97.4 \%$ & 1012.2 & $94,136,243$ & 9827 & 62 & 191,089 & 29.6 & 9579 & 1340 & $5,235,760$ \\
\hline Dirofilaria immitis & III & 12,857 & $98.0 \%$ & 1134.2 & $88,309,529$ & 16,061 & 219 & 71,281 & 28 & 5498 & 754 & $1,085,577$ \\
\hline Loa loa & III & 15,445 & $97.8 \%$ & 987.8 & $91,373,458$ & 5773 & 130 & 174,388 & 31 & 15,828 & 1186 & $1,325,655$ \\
\hline Globodera pallida & IV & 16,403 & $83.8 \%$ & 1079.6 & $124,672,549$ & 6873 & 298 & 121,687 & 36.7 & 18,139 & 1699 & 600,076 \\
\hline Meloidogyne hapla & IV & 14,420 & $97.2 \%$ & 1044.7 & $53,017,507$ & 3452 & 372 & 37,608 & 27.4 & 15,358 & 5814 & 360,446 \\
\hline Caenorhabditis elegans & V & 30,697 & $100.0 \%$ & 1229.5 & $100,286,401$ & 7 & 3 & $17,493,829$ & 35.4 & $14,326,629$ & $15,279,421$ & $20,924,180$ \\
\hline Haemonchus contortus & V & 24,466 & $95.0 \%$ & 1124.8 & $369,846,877$ & 23,860 & 1151 & 83,287 & 43.1 & 15,501 & 1515 & 947,606 \\
\hline Necator americanus & V & 19,153 & $97.2 \%$ & 804.6 & $244,075,060$ & 11,864 & 284 & 211,861 & 40.2 & 20,573 & 1315 & $1,890,151$ \\
\hline Pristionchus pacificus & V & 24,217 & $98.0 \%$ & 994.3 & $172,494,865$ & 18,083 & 39 & $1,244,534$ & 42.8 & 9539 & 685 & $5,268,024$ \\
\hline AC-Orig & V & 16,155 & $98.9 \%$ & 894.3 & $348,994,891$ & 8098 & 263 & 373,206 & 43.5 & 43,096 & 1515 & $2,174,208$ \\
\hline$A C-P B$ & V & 17,540 & & 962.8 & & & & & & & & \\
\hline
\end{tabular}

single-molecule mRNA sequencing) to improve annotation of already existing genome assemblies in GenBank is needed.

To evaluate and quantify improvement of genome annotation in our existing Ancylostoma ceylanicum assembly, we evaluated a long read mRNA library approach using PacBio single molecule real time (SMRT) technology. PacBio sequencing is unique when compared to sequencing-by-synthesis approaches. Read lengths are proportional to reaction times (movie lengths). Thus, PacBio is becoming the gold standard in long read sequencing technologies with average polymerase reads easily exceeding $14 \mathrm{kbp}$ (personal observations). As impressive as the read lengths are in SMRT sequencing, the single pass error rates are also impressively high ( 15\%; Table 2) dominated by insertions and deletions (indels). To compensate, a level of consensus accuracy (>99\%) is achieved with sufficient depth of coverage of long single molecules. In particular, a CCS is derived from multiple sequences from the same circular SMRTbell library template.

In our work, we generated cDNA using total RNA isolated from the adult stage of the parasitic hookworm Ancylostoma ceylanicum (maintained in the Syrian Golden hamster Mesocricetus auratus). Hookworm infections are clinically considered a leading cause of iron deficiency anemia and protein malnutrition, primarily affecting children and pregnant women [4]. Two major hookworm species infecting humans, Necator americanus and $A$. duodenale, collectively infect an estimated 700 million people worldwide, predominantly in South and Central America, sub-Saharan Africa, and East Asia $[5,6]$. However, recent epidemiological studies have identified $A$. ceylanicum as the next dominant hookworm species infecting humans following $N$. americanus in Asia [7-10]. The hamster-derived A. ceylanicum worms have long been utilized in studies of hookworm pathogenesis, vaccine development and anthelmintic

Table 2 P4 Chemistry Sequencing Statistics

\begin{tabular}{|c|c|c|c|c|c|c|c|c|}
\hline \multirow{2}{*}{$\begin{array}{l}\text { Movie } \\
\text { Length } \\
\text { (mins) }\end{array}$} & \multirow{2}{*}{$\begin{array}{l}\text { Total } \\
\text { Bases } \\
\text { (MB) }\end{array}$} & \multicolumn{2}{|c|}{ Polymerase Reads } & \multicolumn{2}{|c|}{ Reads of Insert } & \multicolumn{3}{|c|}{ Zero Mode Waveguide Loading Efficiency } \\
\hline & & Length (bp) & Quality & Length & Quality & (P0) & $(\mathrm{P} 1)$ & $(\mathrm{P} 2)$ \\
\hline 75 & 409.5 & 5858 & 0.84 & 813 & 0.93 & $34,281(23 \%)$ & $69,907(47 \%)$ & $46,104(31 \%)$ \\
\hline 75 & 432.28 & 5938 & 0.84 & 811 & 0.93 & $26,892(18 \%)$ & $72,796(48 \%)$ & $50,604(34 \%)$ \\
\hline 75 & 408.76 & 5837 & 0.84 & 808 & 0.93 & $30,481(20 \%)$ & $70,029(47 \%)$ & $49,782(33 \%)$ \\
\hline 75 & 398.05 & 6142 & 0.84 & 795 & 0.94 & $35,605(24 \%)$ & 64,808 (43\%) & $49,879(33 \%)$ \\
\hline
\end{tabular}


testing since 1970s, due to the similar clinical features presented in hamsters when infected with $A$. ceylanicum as in human hookworm patients and the relative ease of obtaining samples [11-19].

To minimize the repertoire of over-abundant transcripts, we performed cDNA library normalization. In addition, we enriched transcripts based on the $A$. ceylanicum cDNA mode length $(\sim 1.3 \mathrm{~kb})$ by size-selecting $2 \mathrm{~kb}$ PacBio SMRTbell libraries. In all, we generated over 270,000 reads represented by 192,288 CCSs as unique transcript molecules. We then supplemented the previously generated and publicly available Sanger based transcripts [20] with these newly obtained CCSs. To evaluate the improvement of the existing genome annotation, we re-ran the gene prediction pipelines against the existing genome assembly. Comprehensive comparison with the original annotated gene set provided deep understanding of the unique contribution of the PacBio mRNA sequences to the genome annotation.

\section{Results}

\section{PacBio sequencing results}

We used the $A$. ceylanicum genome assembly that we have generated (BioProject PRJNA72583) using a whole genome shotgun approach on the 454/Roche platform. Our 'original' A. ceylanicum genome annotation ("ACOrig", before the inclusion of PacBio data; BioProjectID \# PRJNA72583, GenBank uploaded in May 2013), contained 16,026 predicted genes, and used 10,591 available A. ceylanicum EST sequences (spanning the L3i larva and adult life cycle stages) downloaded from the NCBI database. The AC-Orig annotation and the annotation using the PacBio data (AC-PB) was done on the same genome assembly using the same annotation pipeline (see Methods; Fig. 1).
To improve upon the AC-Orig annotation, we primed total RNA using the SMARTer technology with the goal of polymerizing long 1st-strand cDNA molecules that possess a common $5^{\prime}$ and $3^{\prime}$ PCR priming site for subsequent single primer PCR amplification. This single primer technique only amplifies 1st-strand cDNAs synthesized with both priming sites during the RT reaction, and the amplification products are typically $>500 \mathrm{bp}$ minimizing the representation of smaller cDNA molecules [21]. This is the strategy PacBio uses for their Isoform Sequencing (Iso-Seq) protocol.

Unlike the Iso-Seq protocol, we added a cDNA normalization step to our protocol since each SMRT Cell consists of only 150,000 zero-mode waveguides (ZMWs) with single molecule loading efficiencies in the $30-50 \%$ range. Normalization is one method to minimize overabundant cDNA molecules synthesized from highly expressed transcripts, allow detection of under-represented transcripts, and reduce costs by minimizing the number of SMRT Cells required for data generation. The normalized cDNA length distribution was assessed on the Agilent BioAnalyzer, 2100 (Agilent Technologies, Cedar Creek, Texas; default settings) and the electropherogram revealed cDNA molecules ranged from $500 \mathrm{bp}$ to slightly greater than $2 \mathrm{~kb}$. Using this cDNA source, the generated $2 \mathrm{~kb}$ PacBio SMRT-bell library was subsequently sequenced on the Pacific Bioscience RS.

The normalized, male adult stage $A$. ceylanicum cDNA SMRTbell library was sequenced using the P4 polymerase across four SMRT Cells and imaged for $75 \mathrm{~min}$ (Table 2). This generated 124 million bases from 192,888 CCS with a maximum read length of 3572 bp and a mean CCS read length of 730 bases. Overall, the normalized library produced an additional 124 Mbp of unique data from the same RNA source that was also used to generate Illumina RNA-Seq data. The Illumina RNA-seq
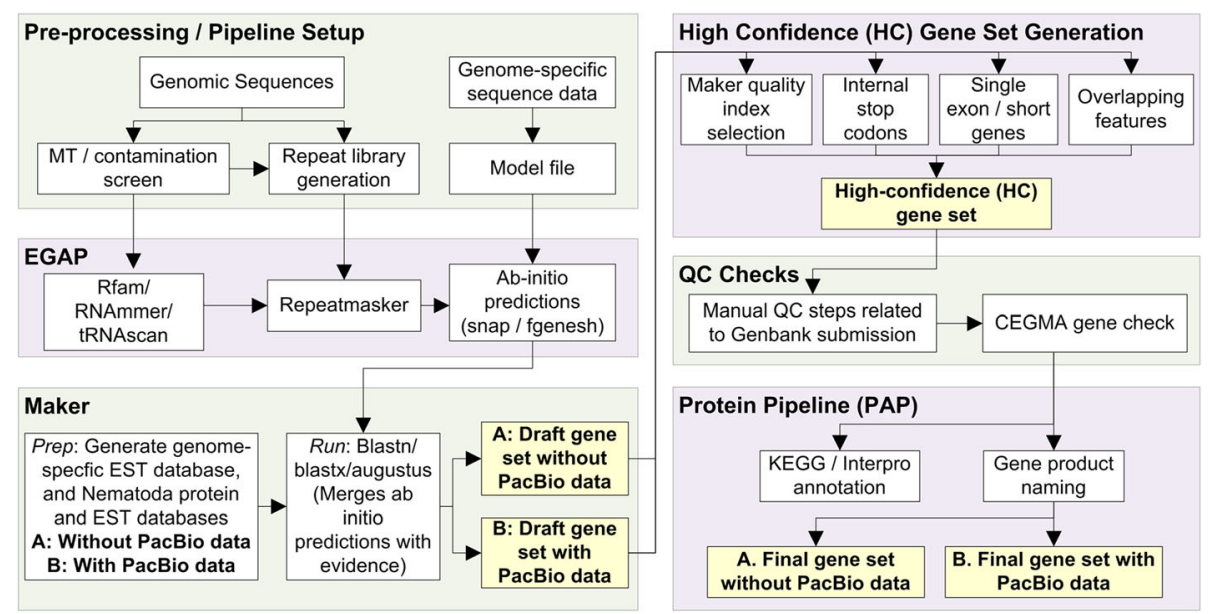

Fig. 1 An overview of the gene prediction process. The gene prediction process, as described in the methods, is divided into major and minor steps 
data was used both at: a) raw RNA-seq reads level, and b) assembled Illumina transcripts level, to compare and orthogonally validate the AC-Orig and AC-PB annotations.

\section{General features of the revised gene prediction}

The newly obtained CCSs, combined with previously downloaded EST sequences [20] were used as transcriptomic evidence and provided to our in-house gene prediction pipeline, consisting of RNA predictors, a combination of ab initio and evidence-based predictors and Maker (Fig. 1).

Our new gene set utilizing the PacBio data (AC-PB) contained 17,540 protein-coding genes, including 1609 genes $(9.2 \%)$ that did not overlap with the previously identified with the original annotation (AC-Orig) (Table 3 ). Approximately 47\% (8238) of the AC-PB genes were mapped by nearly $75 \%(143,666)$ of the PacBio CCSs, with $50.4 \%$ (811) of the AC-PB unique genes being "expressed" (covered by at least $50 \%$ of their length). While the number of AC-Orig and AC-PB genes considered to be expressed based on the coverage with the Illumina RNA-seq reads (42 million RNA-seq reads) was similar $(64.9 \%$ vs. $66.8 \%$, respectively), more of the AC-PB-unique genes were expressed (1356, 84.3\%) than AC-Orig-unique genes (151, 69.3\%).

Of 15,931 AC-PB genes for which the loci overlapped $>10 \%$ with those in AC-Orig, 3965 had increased length (Fig. 2a), while only 1879 decreased in length. The AC$\mathrm{PB}$ genes overlapping the AC-Orig genes were significantly shorter on average (4686.6 bp vs. $5068.1, P=0.02$ by two-tailed T-test with unequal variance; Shapiro Wilk $\mathrm{W}=0.96$, using Log values). Additionally, 328 AC-Orig genes were split into two to four AC-PB genes (692 total; Fig. 2b), and 431 AC-Orig genes were merged into 209 AC-PB genes (Fig. 2c). The new AC-PB predictions represent a $1.9 \mathrm{Mb}$ increase in CDS / exon length compared to AC-Orig (totaling to $7.92 \mathrm{Mb}$ of genomic sequence; Figs. 3a and 1b), although this was accompanied by a $2.2 \mathrm{Mb}$ decrease in intron length (Fig. 3c). Figure 4 demonstrates a specific example in which PacBio reads expand the length of a gene and predict a new gene, where no evidence existed before, within the same genomic region. In addition, the AC-PB-unique genes contained a total of $162,659 \mathrm{bp}$ and $204,894 \mathrm{bp}$ of CDS not covered by Illumina reads or assembled Illumina transcripts (respectively) compared to 67,787 and 77,403 for the AC-Orig unique genes. This resulted in $6.3 \%$ and $16.0 \%$ of AC-PB genes not being covered at all by Illumina reads or assembled Illumina transcripts at all (respectively; Table 4). In addition, 20.1\% (2934) of all assembled Illumina transcripts had no overlap with genes from either assembly ("Illumina-unique"). Of those, 7.8\% (228/2934) had no hits in the NCBI NR database, compared to only $0.05 \%(56 / 11,677)$ for the assembled Illumina transcripts with hits to either gene set. Among the transcripts with hits in NCBI, the average $\log \mathrm{E}$ value of the Illumina-unique transcripts was significantly higher (i.e. a weaker match) than those that overlapped genes $\left(P<10^{-10}\right.$, two-tailed Mann-Whitney $\mathrm{U}$ test), and their average length was also significantly shorter than those that overlapped genes (765.0 vs 1539.5; $P<10^{-10}$, two-tailed Mann Whitney U test).

In addition to increased coding content obtained in the presence of the PacBio long cDNA CCSs, the AC-PB

Table 3 Illumina and Pacbio RNA-Seq read coverage over predicted gene sets

\begin{tabular}{|c|c|c|c|c|c|c|c|}
\hline \multirow{2}{*}{$\begin{array}{l}\text { Read } \\
\text { Type }\end{array}$} & \multirow{2}{*}{$\begin{array}{l}\text { Gene } \\
\text { Set }\end{array}$} & \multirow{2}{*}{$\begin{array}{l}\text { Subset of } \\
\text { genes }\end{array}$} & \multirow{2}{*}{$\begin{array}{l}\text { Total } \\
\text { count }\end{array}$} & \multirow{2}{*}{$\begin{array}{l}\text { \# of } \\
\text { expressed } \\
\text { genes } \\
\text { (breadth } \geq 50 \% \text { ) }\end{array}$} & \multirow{2}{*}{$\begin{array}{l}\% \\
\text { expressed }\end{array}$} & \multicolumn{2}{|c|}{ Average read depth } \\
\hline & & & & & & Any & Expressed \\
\hline \multirow[t]{7}{*}{ Illumina Reads } & \multirow[t]{3}{*}{ AC-Orig } & All genes & 16,026 & 10,405 & $64.9 \%$ & 161.1 & 245.6 \\
\hline & & Overlapping AC-PB genes & 15,808 & 10,254 & $64.9 \%$ & 160.9 & 245.5 \\
\hline & & Not overlapping AC-PB genes & 218 & 151 & $69.3 \%$ & 171.3 & 246.4 \\
\hline & \multirow[t]{3}{*}{ AC-PB } & All genes & 17,540 & 11,721 & $66.8 \%$ & 156.3 & 231.6 \\
\hline & & Overlapping AC-Orig genes & 15,931 & 10,365 & $65.1 \%$ & 158.3 & 240.8 \\
\hline & & Not overlapping AC-Orig genes & 1609 & 1356 & $84.3 \%$ & 136.5 & 161.1 \\
\hline & \multicolumn{2}{|c|}{ Schwarz et al., [31] } & 36,687 & 16,376 & $44.6 \%$ & 90.4 & 199.4 \\
\hline \multirow[t]{7}{*}{ PacBio Reads } & \multirow[t]{3}{*}{ AC-Orig } & All genes & 16,026 & 3166 & $19.8 \%$ & 3.3 & 8.9 \\
\hline & & Overlapping AC-PB genes & 15,808 & 3128 & $19.8 \%$ & 3.2 & 8.8 \\
\hline & & Not overlapping AC-PB genes & 218 & 38 & $17.4 \%$ & 4.1 & 12.8 \\
\hline & \multirow[t]{3}{*}{$A C-P B$} & All genes & 17,540 & 4209 & $24.0 \%$ & 3.6 & 8.8 \\
\hline & & Overlapping AC-Orig genes & 15,931 & 3398 & $21.3 \%$ & 3.4 & 8.7 \\
\hline & & Not overlapping AC-Orig genes & 1609 & 811 & $50.4 \%$ & 6.4 & 9.1 \\
\hline & \multicolumn{2}{|c|}{ Schwarz et al., [31] } & 36,687 & 4903 & $13.4 \%$ & 2.1 & 8.8 \\
\hline
\end{tabular}



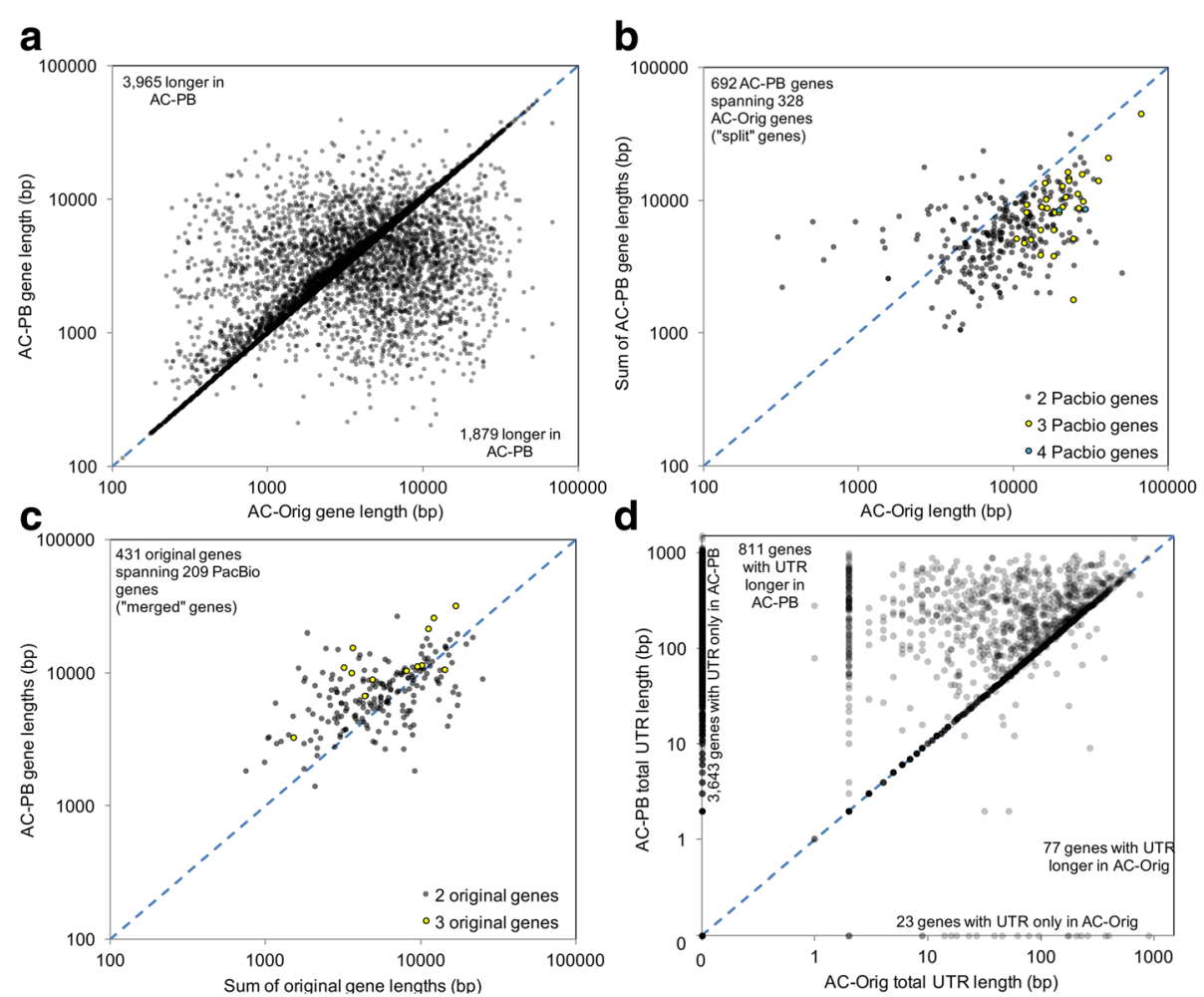

Fig. 2 Differences in gene lengths and UTR lengths between AC-Orig and AC-PB. Differences in gene lengths are shown for: a Genes not split or merged between the annotations, (b) Genes split in AC-PB compared to AC-Orig, and (c) Genes merged in AC-PB compared to AC-Orig. $\mathbf{d}$ Differences in UTR lengths (summed for $5^{\prime}$ and $3^{\prime}$ ) between AC-Orig and AC-PB. Additional file 1 shows the UTR lengths separate for $5^{\prime}$ and $3^{\prime}$ regions

data set demonstrated a fifteen-fold increase in noncoding representation, primarily from an increase in UTRs (Fig. 2d; Table 5; Additional file 1). The largest increase was observed in the base representation of the 3' UTRs (Additional file 1, panel a), with an overall increase of $1.4 \mathrm{Mb}$ and a total representation of $1.8 \mathrm{Mb}$, but there was also a large improvement in 5' UTR representation (Additional file 1, panel b), and improved noncoding representation, from $40 \mathrm{~kb}$ to greater than $270 \mathrm{~kb}$. Additionally, the number of genes with 3' UTRs and 5' UTR increased by 5-fold and 3-fold (respectively), with a nearly 2 -fold increase in overall UTR lengths (Fig. 2d, Table 5), and a significant increase in average identified 3' UTR length (233.2 bp in AC-PB vs 81.0 bp in AC-Orig, $P<10^{-10}$ by Mann-Whitney U test; Fig. $3 \mathrm{~d}$ ) and 5' UTR length (88.2 bp in AC-PB vs 57.7 bp in ACOrig, $\mathrm{P}<10^{-10}$ by Mann-Whitney $U$ test; Fig. 3e). In the genes exclusive to only one annotation or the other, there were far more AC-PB unique genes with 5' UTRs (702) than AC-Orig unique (18), and these were also significantly longer (average of $104.8 \mathrm{bp}$ vs $24.3 \mathrm{bp}$ for ACOrig unique, $\left.P=5 \times 10^{-5}\right)$. Overall, 23,279 bp and 29,761 bp of the AC-PB unique genes were not covered by Illumina RNA-seq reads or assembled Illumina transcripts (respectively, compared to just 58 bp and 48 bp for AC-Orig unique genes). This resulted in $25.8 \%$ and $23.8 \%$ of $\mathrm{AC}-\mathrm{PB}$ unique genes with 5 'UTR having no Illumina coverage whatsoever (Table 5 ).

We observed that 3'-UTRs resided mostly (79\% for AC-Orig and $97 \%$ for AC-PB) within a single exon flanking the CDS, but the number of 3' UTRs containing spliced exons were significantly higher in the AC-PB gene set (400 vs 45 in AC-Orig). For non-spliced UTRs, the lengths of exons where UTRs resided were longer in AC-PB (1,504,453 compared to 124,243 for AC-Orig) and in higher number (6165 compared to 1684 for ACOrig). For overlapping genes with UTR exons, the UTRs were longer on average in AC-PB for both the 3' UTR exons (224.0 bp vs 76.4 bp in AC-Orig, $\mathrm{P}<10^{-10}$ by Mann-Whitney U test) and the 5' UTR exons (45.8 bp vs 35.9 bp in AC-Orig, $P=1 \times 10^{-6}$ ). In the genes exclusive to only one annotation or the other, there were far more AC-PB unique genes with 3' UTRs (1245) than AC-Orig unique (16), and these were also significantly longer (average of 221.0 bp vs 52.3 bp for AC-Orig unique, $\mathrm{P}=5 \times 10^{-6}$ ). Overall, $111,123 \mathrm{bp}$ and 79,177 bp of 3' UTRs from AC-PB unique genes were not covered by any Illumina RNA-seq reads or assembled Illumina transcripts (respectively, compared to just $334 \mathrm{bp}$ and 204 bp for AC-Orig unique genes). This resulted in 

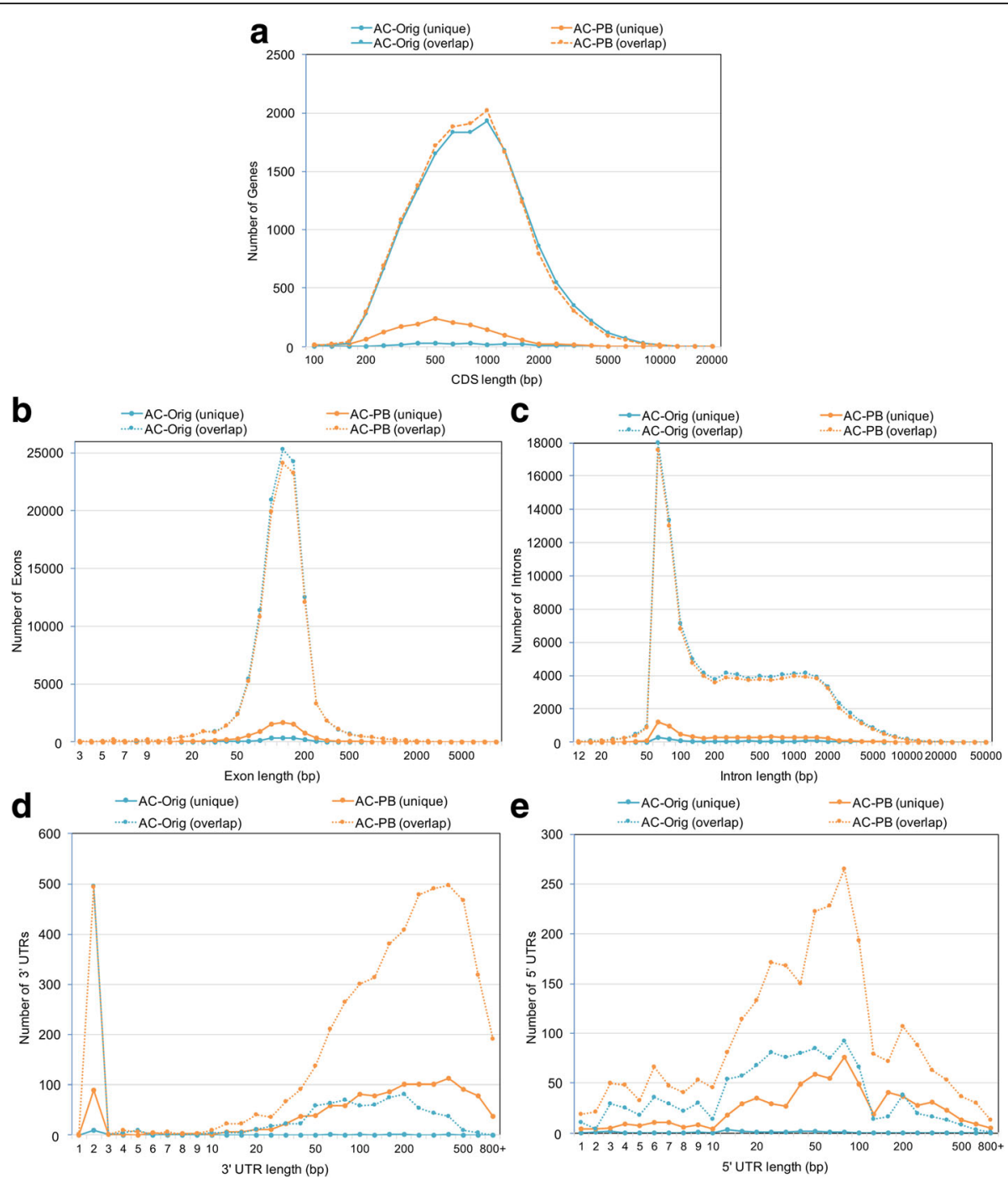

Fig. 3 Frequency distribution plots for AC-Orig (blue) and AC-PB (orange) for (a) CDS Lengths, (b) Exon lengths, (c) Intron lengths, (d) 3' UTRs and (e) 5' UTRs

$32.5 \%$ and $34.7 \%$ of $\mathrm{AC}-\mathrm{PB}$ unique genes with 3'UTR having no Illumina coverage whatsoever (Table 5). Overall, AC-PB genes identified $0.51 \mathrm{Mbp}$ and $0.35 \mathrm{Mbp}$ of 3'UTR not covered by Illumina reads or assembled transcripts (respectively). These findings show that the UTR length changes observed in AC-PB can be attributed to both an increased number of identified UTR exons as well as increased lengths of the existing UTR exons.

Increased representation of full-length transcript by CCSs The increased number of $55^{\prime} / 3$ ' UTRs identified in ACPB suggested that transcriptomic evidence supplemented with PacBio CCSs provides additional information useful for annotating full-length transcripts. Sequence analysis revealed that 15,993 PacBio CCSs contained complete open reading frames (ORFs) and corresponding 5'/3'
UTRs for 2800 genes, while AC-Orig contained complete ORFs and UTRs for only 239 genes.

We also extracted UTR features from full-length $A$. ceylanicum transcripts and searched them for 22-nt spliced leader sequences (SLs). SL1 is conserved across nematode species, and genes with SL1 have previously been cloned from A. ceylanicum [22, 23]. In addition to SL1s, polyA signals (PASs) are a feature of eukaryotic protein-coding genes, defining the transcription termination site. Most PASs are conserved with sequence motifs of "AATAAA" or the close variant "ATTAAA" [24, 25]. We obtained all the ESTs/PacBio CCSs that were aligned to the $5^{\prime} / 3^{\prime}$-UTRs, and then performed the direct searches of the 5' SL sequences and 3' PASs on those ESTs/PacBio CCSs. We found that 18,115 and 101,684 of our long RNA-Seq CCSs were aligned to the 5'-UTRs of 3765 genes and 3'-UTRs of 7321 genes (respectively). 


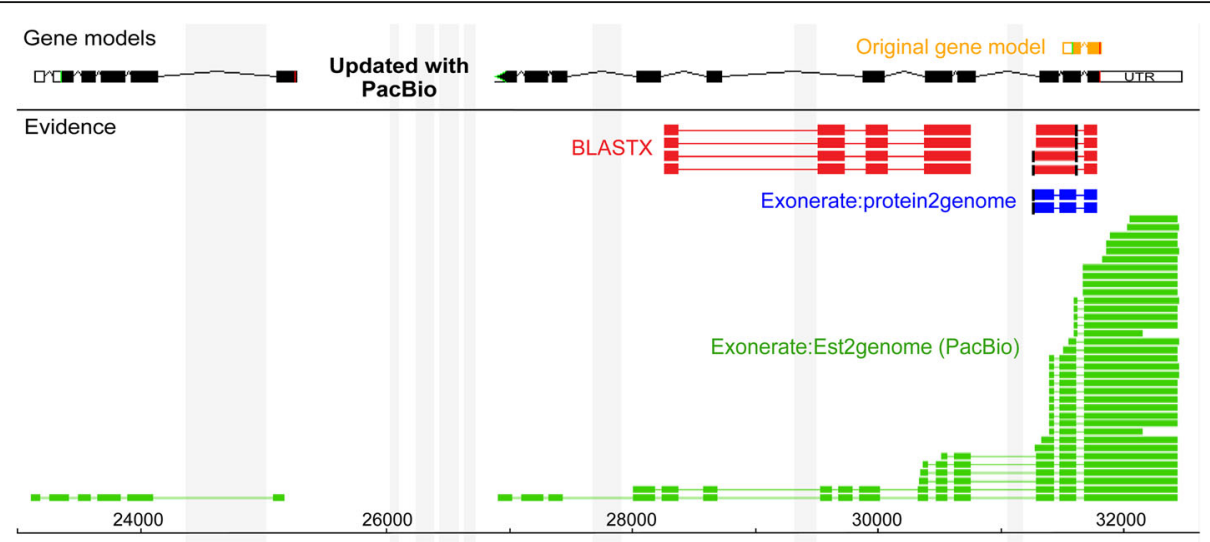

Fig. 4 An example of an improved gene structure predictions in AC-PB (black) compared to AC-Orig (orange). The BLASTX (red) and protein2genome (blue) predictions used for AC-Orig predicted a short gene model, but additional PacBio evidence (green) extended the existing gene, and also predicted a second gene at the 5' end of the original gene. Shaded grey areas represent masked repeat sequences in the assembly

In contrast, only 1729 and 3369 downloaded ESTs were aligned to the $5^{\prime}$ and 3' UTRs of predicted A. ceylanicum genes, (respectively), further suggesting the importance of PacBio CCSs in UTR identification. Among all the PacBio CCSs aligned to 5' UTRs, 115 (corresponding to 108 genes) contained SL1 sequences, and 19 (corresponding to 18 genes) contained SL2 sequences. Using the AC-PB data, we were able to identify a base switch at positions $15 / 16$ in SL2 compared to C. elegans, which is a novel finding since the SL2 sequence has never previously been reported for $A$. ceylanicum (C. elegans: GGTTTTAACC CAGTTACTCAAG, A. ceylanicum: GGTTTTAACCCA GTATCTCAAG). Similarly, PASs in 3'-UTRs were much more highly represented in PacBio CCSs (49,926 CCSs / 4086 genes) compared to ESTs (538 ESTs). PASs detected with PacBio had a mean distance to the stop codon of 214 nt. One striking feature was the low number of polyA/polyT sequences present in $3^{\prime}$ end CCSs (1662 out of 49,926 CCSs).

\section{Gene sets annotated with PacBio reads have increased overall functional potential}

Functional analysis of the annotated gene sets was performed by searching the KEGG database (Additional file 2) [26]. The results showed an increase KEGG matches in the AC-PB predictions (15,226 genes, $86.8 \%$ of AC-PB genes) when compared with AC-Orig (12,995 genes, $81.1 \%$ of AC-Orig genes), as well as an increase in the number of unique KEGG orthologous groups identified (3923 vs 3711, respectively; 3600 in common). The most expanded KEGG pathway was the broad parent category "Metabolic Pathways" (ko1100), with 36 (5.8\%) more KEGG Orthologous group classifications (KOs) and 291 more genes (13.7\%) annotated to this pathway in AC-PB compared to AC-Orig. The second most expanded pathway among AC-PB was "Biosynthesis of secondary metabolites" (13 additional KOs and 89 additional genes), which is an important pathway for studying signaling between parasitic nematodes and hosts, as well as with their symbiotic bacteria [27-29]. Another strongly expanded pathway, "MAPK signaling" (ko4010) (2 additional KOs and 41 additional genes; $19.4 \%$ increase) is important for environmental signaling and stress responses in nematodes [30]. Counts of KOs and genes per pathway are shown in Additional file 2.

\section{Discussion}

To facilitate a better understanding of hookworm biology, tracking hookworm infection history and distribution, and eventually developing effective intervention strategies that can be applied to all the hookworm diseases, determining their genome information is a prerequisite. In addition to the de novo genome assembly of A. ceylanicum presented here, we have also published a de novo genome assembly of $N$. americanus with 19,542 annotated genes [1]. Annotating these hookworm genomes has been challenging due to insufficient transcriptomic evidence obtained either using the secondgeneration 454/Roche pyro-sequencing or Sanger sequencing, and only recently Illumina platform. The Sanger sequencing is labor-intensive and low-throughput, even though the generated reads are long $(\sim 750 \mathrm{bp})$ and with high accuracy. 454/Roche-pyro sequencing is relatively cost-effective and high-throughput, but the reads are typically short, with high base-composition bias. Therefore, the resultant hookworm genome drafts and annotated genes were often missing start/stop codons and un-translated region (UTR) annotations. In addition, evidence of long non-coding RNAs (lncRNAs) and transcript isoforms are either undefined or underestimated. Complex eukaryotic genome assemblies and annotations required time and effort to be generated and many of them never get 
Table 4 Summary of CDS and 5' and 3' Untranslated Region (UTR) statistics, including overlaps between gene sets and with assembled Illumina transcripts and RNAseq Illumina reads

\begin{tabular}{|c|c|c|c|c|c|c|c|c|}
\hline \multirow{2}{*}{$\begin{array}{l}\text { Gene } \\
\text { region }\end{array}$} & \multirow[t]{2}{*}{ Statistic } & & \multicolumn{3}{|l|}{ AC-Orig } & \multicolumn{3}{|l|}{$A C-P B$} \\
\hline & & & $\begin{array}{l}\text { All } \\
\text { genes }\end{array}$ & $\begin{array}{l}\text { Overlapping } \\
\text { genes }\end{array}$ & $\begin{array}{l}\text { Unique } \\
\text { genes }\end{array}$ & $\begin{array}{l}\text { All } \\
\text { genes }\end{array}$ & $\begin{array}{l}\text { Overlapping } \\
\text { genes }\end{array}$ & $\begin{array}{l}\text { Unique } \\
\text { genes }\end{array}$ \\
\hline \multirow[t]{9}{*}{ CDS } & \multicolumn{2}{|l|}{ \# of genes } & 16,026 & 15,808 & 218 & 17,540 & 15,931 & 1609 \\
\hline & \multicolumn{2}{|l|}{ Average length (bp) } & 962.8 & 962.4 & 994.3 & 894.3 & 922.0 & 619.8 \\
\hline & \multicolumn{2}{|l|}{ Total length (kbp) } & $15,430.0$ & $15,213.2$ & 216.8 & $15,685.3$ & $14,688.0$ & 997.3 \\
\hline & \multirow{3}{*}{$\begin{array}{l}\text { Coverage by } \\
\text { Illumina reads }\end{array}$} & $\%$ of genes & $78.1 \%$ & $78.0 \%$ & $80.7 \%$ & $79.6 \%$ & $78.2 \%$ & $93.7 \%$ \\
\hline & & $\%$ of bases & $66.9 \%$ & $66.8 \%$ & $68.7 \%$ & $67.5 \%$ & $66.4 \%$ & $83.7 \%$ \\
\hline & & Length not covered (kbp) & 5111.7 & 5043.9 & 67.8 & 5104.8 & 4942.2 & 162.7 \\
\hline & \multirow{3}{*}{$\begin{array}{l}\text { Coverage by Illumina } \\
\text { Stringtie contigs }\end{array}$} & $\%$ of genes & $65.2 \%$ & $65.1 \%$ & $67.9 \%$ & $66.9 \%$ & $64.8 \%$ & $84.0 \%$ \\
\hline & & $\%$ of bases & $61.8 \%$ & $61.8 \%$ & $64.3 \%$ & $62.4 \%$ & $61.2 \%$ & $79.5 \%$ \\
\hline & & Length not covered (kbp) & 5895.8 & 5818.4 & 77.4 & 5899.6 & 5694.7 & 204.9 \\
\hline \multirow[t]{9}{*}{$5^{\prime}$ UTR } & \multicolumn{2}{|l|}{ \# of genes } & 1101 & 1083 & 18 & 3404 & 2702 & 702 \\
\hline & \multicolumn{2}{|l|}{ Average length (bp) } & 57.7 & 58.2 & 24.3 & 88.2 & 83.9 & 104.8 \\
\hline & \multicolumn{2}{|l|}{ Total length (kbp) } & 63.5 & 63.1 & 0.4 & 300.2 & 226.7 & 73.6 \\
\hline & \multirow{3}{*}{$\begin{array}{l}\text { Coverage by } \\
\text { Illumina reads }\end{array}$} & $\%$ of genes & $74.1 \%$ & $74.1 \%$ & $72.2 \%$ & $78.7 \%$ & $79.8 \%$ & $74.2 \%$ \\
\hline & & $\%$ of bases & $61.5 \%$ & $61.3 \%$ & $89.7 \%$ & $73.1 \%$ & $74.7 \%$ & $68.4 \%$ \\
\hline & & Length not covered (kbp) & 18.7 & 18.6 & 0.1 & 80.7 & 57.4 & 23.3 \\
\hline & \multirow{3}{*}{$\begin{array}{l}\text { Coverage by Illumina } \\
\text { Stringtie contigs }\end{array}$} & $\%$ of genes & $77.3 \%$ & $77.2 \%$ & $83.3 \%$ & $79.5 \%$ & $80.4 \%$ & $76.2 \%$ \\
\hline & & $\%$ of bases & $70.6 \%$ & $70.5 \%$ & $86.7 \%$ & $66.8 \%$ & $69.2 \%$ & $59.5 \%$ \\
\hline & & Length not covered (kbp) & 24.5 & 24.4 & 0.0 & 99.5 & 69.8 & 29.8 \\
\hline \multirow[t]{9}{*}{ 3' UTR } & \multicolumn{2}{|l|}{ \# of genes } & 1234 & 1218 & 16 & 6608 & 5363 & 1245 \\
\hline & \multicolumn{2}{|l|}{ Average length (bp) } & 78.4 & 78.8 & 52.3 & 232.1 & 234.7 & 221.0 \\
\hline & \multicolumn{2}{|l|}{ Total length (kbp) } & 96.8 & 95.9 & 0.8 & 1533.9 & 1258.8 & 275.1 \\
\hline & \multirow{3}{*}{$\begin{array}{l}\text { Coverage by } \\
\text { Illumina reads }\end{array}$} & $\%$ of genes & $50.1 \%$ & $50.3 \%$ & $31.3 \%$ & $73.3 \%$ & $74.6 \%$ & $67.5 \%$ \\
\hline & & $\%$ of bases & $73.9 \%$ & $73.9 \%$ & $75.6 \%$ & $77.0 \%$ & $78.2 \%$ & $71.2 \%$ \\
\hline & & Length not covered (kbp) & 31.1 & 30.8 & 0.3 & 513.6 & 402.5 & 111.1 \\
\hline & \multirow{3}{*}{$\begin{array}{l}\text { Coverage by Illumina } \\
\text { Stringtie contigs }\end{array}$} & $\%$ of genes & $56.3 \%$ & $56.7 \%$ & $25.0 \%$ & $70.4 \%$ & $71.5 \%$ & $65.3 \%$ \\
\hline & & $\%$ of bases & $67.9 \%$ & $67.9 \%$ & $60.0 \%$ & $66.5 \%$ & $68.0 \%$ & $59.6 \%$ \\
\hline & & Length not covered (kbp) & 25.3 & 25.1 & 0.2 & 353.1 & 273.9 & 79.2 \\
\hline
\end{tabular}

improved overtime. Providing a detailed quantification of the level of improved annotation using different mRNA sequencing technologies without re-sequencing the genome provides valuable information to make an informed decision.

With the exceptional SMRT sequencing technology introduced by PacBio, we generated the deepest and the longest long-read dataset to date for the A. ceylanicum transcriptome. These long PacBio CCSs were used to complement the existing ESTs (AC-Orig) and a revised A. ceylanicum gene prediction (AC-PB) was obtained. The results showed that $92.2 \%$ of the PacBio CCSs $(177,843 / 192,888)$ were mapped to the A. ceylanicum genome (94.2\% mapped to the published version of the genome [31]), indicating the consensus sequences are of high quality. The revised gene predictions revealed $2 \mathrm{MB}$ of new coding regions and identified 1609 new genes when compared with the previous version ACOrig which only used available ESTs as transcriptomic evidence.

In addition to the merging of many split genes, one of the distinctive features of $\mathrm{AC}-\mathrm{PB}$ in comparison with AC-Orig was the increase in number and length of UTRs, particularly 3' UTRs, clearly demonstrating the advantage of long CCSs in defining gene UTRs and consequently more complete ORFs. Compelling evidence has shown that UTR regions correlate with the complexity of gene expression regulation in eukaryotic organisms [32], furthering the importance of PacBio platform in gene discovery and identifying gene boundaries with increased number of UTRs and UTRs containing splicing sites. Here, we also identify 134,390 bp of UTR among genes only identified by PacBio annotation which were 
Table 5 A Summary of characteristics of assemblies annotated without and with PacBio mRNA sequences

\begin{tabular}{|c|c|c|c|c|}
\hline Statistic & $\begin{array}{l}\text { Original A. ceylanicum } \\
\text { genome annotation } \\
\text { (AC-Orig) }\end{array}$ & $\begin{array}{l}\text { Improved } A \text {. ceylanicum } \\
\text { genome annotation } \\
\text { using PacBio data (AC-PB) }\end{array}$ & $\begin{array}{l}\text { AC-Orig genes } \\
\text { overlapping (10\%) AC-PB } \\
\text { genes with PacBio evidence }\end{array}$ & $\begin{array}{l}\text { AC-PB genes with } \\
\text { PacBio evidence } \\
\text { (with or without EST evidence) }\end{array}$ \\
\hline $\begin{array}{l}\text { Number of } \\
\text { genes }\end{array}$ & 16,026 & 17,540 & 6734 & 8238 \\
\hline $\begin{array}{l}\text { Number of } \\
\text { single exon genes }\end{array}$ & 805 & 863 & 154 & 211 \\
\hline $\begin{array}{l}\text { Total length } \\
\text { of all exons (bp) }\end{array}$ & $15,590,301$ & $17,519,546$ & $7,915,169$ & $9,931,507$ \\
\hline $\begin{array}{l}\text { Total number } \\
\text { of exons }\end{array}$ & 117,877 & 121,578 & 63,273 & 67,714 \\
\hline $\begin{array}{l}\text { Average exon } \\
\text { length (bp) }\end{array}$ & 132.3 & 144.1 & 125.1 & 146.7 \\
\hline $\begin{array}{l}\text { Average \# } \\
\text { exons/gene }\end{array}$ & 7.4 & 6.9 & 9.4 & 8.2 \\
\hline $\begin{array}{l}\text { Total length } \\
\text { of all CDS } \\
\text { exons (bp) }\end{array}$ & $15,429,981$ & $15,685,322$ & $28,877,304$ & $27,490,435$ \\
\hline $\begin{array}{l}\text { Total number } \\
\text { of CDS exons }\end{array}$ & 117,657 & 119,866 & 63,129 & 66,083 \\
\hline $\begin{array}{l}\text { Average CDS } \\
\text { exon length (bp) }\end{array}$ & 131.1 & 130.9 & 123.5 & 123.2 \\
\hline $\begin{array}{l}\text { Average \# } \\
\text { coding exons/gene }\end{array}$ & 7.3 & 6.8 & 9.4 & 8.0 \\
\hline $\begin{array}{l}\text { Total length } \\
\text { of all introns (bp) }\end{array}$ & $63,133,642$ & $60,868,345$ & $28,930,431$ & $28,142,643$ \\
\hline $\begin{array}{l}\text { Total number } \\
\text { of introns }\end{array}$ & 101,851 & 104,038 & 56,566 & 59,476 \\
\hline $\begin{array}{l}\text { Average intron } \\
\text { length (bp) }\end{array}$ & 621.2 & 594.9 & 511.7 & 473.2 \\
\hline $\begin{array}{l}\text { Average \# } \\
\text { introns/gene }\end{array}$ & 6.4 & 5.9 & 8.4 & 7.2 \\
\hline $\begin{array}{l}\text { Total UTR } \\
\text { length (bp) }\end{array}$ & 160,320 & $1,834,224$ & 117,930 & $1,788,957$ \\
\hline $\begin{array}{l}\text { Number of } \\
\text { genes with UTR }\end{array}$ & 1889 & 7295 & 1205 & 6567 \\
\hline $\begin{array}{l}\text { Average size of } \\
\text { UTR per gene } \\
\text { with UTR }\end{array}$ & 84.9 & 251.4 & 97.9 & 272.4 \\
\hline $\begin{array}{l}\text { Number of } \\
\text { genes with } \\
\text { UTR }<10 \text { bp }\end{array}$ & 1228 & 3966 & 744 & 3451 \\
\hline $\begin{array}{l}\text { Number of genes with UTR } 10 \mathrm{bp} \text { - } \\
100 \mathrm{bp}\end{array}$ & 423 & 1058 & 287 & 908 \\
\hline $\begin{array}{l}\text { Number of genes with UTR > } \\
100 \mathrm{bp}\end{array}$ & 238 & 2271 & 174 & 2208 \\
\hline Total 5' UTR length (bp) & 63,556 & 300,333 & 39,954 & 273,401 \\
\hline Number of genes with $5^{\prime}$ UTR & 1150 & 3488 & 710 & 3013 \\
\hline $\begin{array}{l}\text { Number of genes with spliced } 5^{\prime} \\
\text { UTR }\end{array}$ & 127 & 745 & 82 & 696 \\
\hline $\begin{array}{l}\text { Total 3' UTR } \\
\text { length (bp) }\end{array}$ & 96,764 & 1533,891 & 77,976 & 1515,556 \\
\hline Number of genes with $3^{\prime}$ UTR & 1238 & 6611 & 817 & 6145 \\
\hline Number of genes with & 45 & 400 & 33 & 388 \\
\hline
\end{tabular}


Table 5 A Summary of characteristics of assemblies annotated without and with PacBio mRNA sequences (Continued)

\begin{tabular}{lllll}
\hline Statistic & $\begin{array}{l}\text { Original A. ceylanicum } \\
\text { genome annotation } \\
\text { (AC-Orig) }\end{array}$ & $\begin{array}{l}\text { Improved A. ceylanicum } \\
\text { genome annotation } \\
\text { using PacBio data (AC-PB) }\end{array}$ & $\begin{array}{l}\text { AC-Orig genes } \\
\text { overlapping (10\%) AC-PB } \\
\text { genes with PacBio evidence }\end{array}$ & $\begin{array}{l}\text { AC-PB genes with } \\
\text { (with or without EST evidence) }\end{array}$ \\
\hline \# of ESTs at 3' & - & - & 3610 & 105,053 \\
polyA signal 'aataaa/attaaa' & - & - & 1307 & 61,069 \\
polyA signal 'agtaaa' only & - & - & 215 & 7775 \\
polyA total (any signal) & - & - & 1522 & 68,844 \\
\hline
\end{tabular}

also not identified by Illumina RNAseq reads, further highlighting the importance of PacBio sequencing annotation in comprehensive UTR annotation. These results were consistent with the common perception that an individual PacBio CCS from our SMARTer-SMRT library would represent all the information originating from a single RNA molecule.

Although PacBio CCSs significantly improved gene predictions, sequences at the end of the transcripts were still missing, as evidenced by low detection rates of SLs and polyA tails. Possible explanations for this phenomenon include incomplete transcripts due to minor RNA degradation based on the 8.9 RIN value, or that we did not specifically enrich for 5' mRNAs using a cap-trapping strategy. Here, we relied on the ability of the SMARTer strand-displacement method to provide $5^{\prime}$ transcript information and carefully highlight this is a long (not a full-length) cDNA method as opposed to the Iso-Seq fulllength claims. This approach highlights near full-length transcript representation [33]. We also noticed that some polyAs were present in the middle of PacBio CCSs, suggesting possible lysine-rich structural genes as associated with basic proteins or potentially inappropriate joining of two transcript fragments. Meanwhile, a strong bias toward the 3' UTR identification existed, which is a result from the oligo $\mathrm{dT}$ priming resulting in cDNAs representing truncated transcripts due to RNA degradation or inefficiency during the reverse transcription reaction. To improve on the 5 ' UTR representation in our long cDNA protocol, one could add an additional cap-trapping strategy enriching for 5' mRNA transcript representation. Other expected improvements could come due to use of a new chemistry (beyond C4) or moving to other PacBio platforms (RSII vs. Sequel).

\section{Conclusions}

Overall, our normalized, long cDNA method generated $>190,000 \mathrm{CCS}$, and our pipeline improvements identified 1609 (9.2\%) new A. ceylanicum genes, extended the length of 3965 (26.7\%) genes and increased the total genomic exon length by $1.9 \mathrm{Mb}$ (12.4\%). Non-coding sequence representation (primarily from UTRs) was particularly improved, increasing in total length by fifteenfold, by increasing both the length and number of UTR exons. In addition, the UTR data provided by PacBio reads allowed for the identification of a novel SL2 splice leader sequence for $A$. ceylanicum and an increase in the number and proportion of functionally annotated genes. In conclusion, PacBio data has supported a significant improvement in gene annotation in this draft genome, and is an appealing alternative or complementary approach to annotation obtained by using other transcript sequencing technologies.

\section{Methods \\ A. ceylanicum collection and preparation}

An Indian strain of $A$. ceylanicum (US National Parasite Collection No. 102954) was maintained in Syrian hamsters (Mesocricetus auratus) as described previously [13]. All animal experiments were carried out in strict accordance with the recommendations in the Guide for the Care and Use of Laboratory Animals of the National Institutes of Health and under protocols approved by the George Washington University Institutional Animal Care and Use Committee. Hamsters with mature infections (greater than 21 days) were euthanized by $\mathrm{CO} 2$ overdose, and the small intestine removed, split longitudinally, and incubated in RPMI medium for $1-2 \mathrm{~h}$ to allow the adult worms to detach from the intestinal wall. The worms were collected by hand, washed 5 times with sterile RPMI medium, snap-frozen by immersion in liquid nitrogen, and stored at $-80 \mathrm{C}$ until used for nucleic acid isolation.

Infective third-stage larvae (iL3) were recovered from coprocultures after approximately one week at $27^{\circ} \mathrm{C}$ by modified Baermann technique and stored up to 4 weeks in BU buffer (50 mM Na2HPO4/22 mM KH2PO4/ $70 \mathrm{mM} \mathrm{NaCl}, \mathrm{pH}$ 6.8) [34] at room temperature prior to infection. A male hamster was infected with approximately $80 \mathrm{~A}$. ceylanicum iL3 by oral gavage. At day 16 post infection (PI), the hamster was sacrificed and the small intestine opened longitudinally in PBS kept at 37 $\mathrm{C}$ on a slide warmer for several hours until the worms released from the intestinal wall. The worms were individually transferred to a dish containing warm PBS using a transfer pipette and incubated for 30-60 min to allow them to disgorge ingested host tissue. The worms were individually transferred to a second dish for $30 \mathrm{~min}$, then 
picked into a microcentrifuge tube containing PBS. The worms were washed by vortex and allowed to settle, and the liquid removed. The washes were repeated until any remaining host tissue was removed. The worms were snap frozen in liquid nitrogen and stored at $-80 \mathrm{C}$ until used for RNA extraction.

Total RNA was extracted from ten 16 day PI male $A$. ceylanicum using Trizol (Thermo Fisher) according to the manufacturer's instructions. Following precipitation, the RNA was resuspended in nuclease free water and treated with DNAse I (Thermo Fisher) for $15 \mathrm{~min}$ at $22 \mathrm{C}$. To stop the reaction, $2.5 \mathrm{mM}$ EDTA was added and the reaction heated at $65 \mathrm{C}$ for $10 \mathrm{~min}$.

\section{A. ceylanicum cDNA preparation}

As input into our long cDNA protocol, we started with $450 \mathrm{ng}$ of DNase-treated total RNA prepared from A. ceylanicum with a corresponding RNA integrity number (RIN) of 8.9. We followed the SMARTer PCR cDNA Synthesis Kit protocol (Clontech Laboratories, Inc., Mountain View, CA; \#634925), briefly highlighted: first-strand cDNAs synthesis was performed by oligo dT annealing and reverse transcription at $42{ }^{\circ} \mathrm{C}$ for $90 \mathrm{~min}$. During this incubation, terminal-transferase activity associated with the reverse transcriptase sequentially adds 3 -cytosines onto the polymerized first strand. This poly-cytosine overhang anneals with 3 '-guanosines as part of the 5' SMART IIA oligo (included in the RT reaction). Template switching during the RT reaction extends the first strand $\mathrm{CDNA}$ and incorporates the complement of the 5' SMART IIA oligo. Depending on the condition of the RNA, this system may generate full-length cDNAs as well as nearly full-length (long) cDNA molecules. These long firststranded cDNA molecules are subsequently amplified during single primer PCR amplification enriching for product sizes $>500$ bp [21] Primers are as described in the Smart IIA documentation (Clontech Laboratories, Inc., Mountain View, CA; \#634925).

Prior to single primer amplification, PCR optimization was used to minimize potential amplification artifacts with the long cDNAs. We added $1 \mu \mathrm{L}$ of 1 st Strand cDNA with SYBRFAST Universal 2X qPCR Master Mix (Biosystems, Inc., Woburn, MA.) and $200 \mathrm{nM}$ primer IIA 5'-AAGCAGTGGTAACAACGCAGAGT. The cDNA was amplified with the Eppendorf epigradient $\mathrm{S}$ qPCR instrument ( $98^{\circ} 2 \mathrm{~min}, 30$ cycles of $98^{\circ} 10 \mathrm{~s} 65^{\circ} \mathrm{C} 30 \mathrm{~s}$ ). The optimal PCR cycle threshold $(\mathrm{Ct})$ for long cDNA amplification was determined using the RealPlex 2.2 software (Eppendorf). The Ct value was 14 cycles. We performed sixteen independent cDNA amplification reactions using $25 \mu \mathrm{l}$ KAPA $2 \times$ HiFi HotStart Ready mix, $1 \mu$ l 1st Strand cDNA, and $200 \mathrm{nM}$ Primer IIA. We used the following cycling conditions: $5 \mathrm{~min}$ at $95{ }^{\circ} \mathrm{C}$, followed by 14 cycles of $30 \mathrm{~s}$ at $95{ }^{\circ} \mathrm{C}, 30 \mathrm{~s}$ at $65{ }^{\circ} \mathrm{C}$, and
3 min at $68{ }^{\circ} \mathrm{C}$. The PCR-amplified second-strand cDNA was concentrated using QIAquick PCR Purification Kit column (Qiagen Inc., Valencia, CA).

To minimize the potential representation of over abundant transcripts and reduce the required number of SMRT Cells for unique transcript identification, we normalized the cDNA using the Trimmer-2 cDNA normalization kit following the manufacture's instruction (Evrogen JSC, Moscow, Russia). In brief, 300 ng aliquots of cDNA was denatured for $2 \mathrm{~min}$ at $98{ }^{\circ} \mathrm{C}$ followed by hybridization for $5 \mathrm{~h}$ at $68{ }^{\circ} \mathrm{C}$ under mineral oil. The re-annealed secondstrand cDNA in each aliquot was digested for $10 \mathrm{~min}$ at $68{ }^{\circ} \mathrm{C}$ with $1 \mathrm{U}$ of Trimmer duplex-specific nuclease (DSN) to obtain the normalized cDNA. The mineral oil was removed and the samples were combined. The normalized cDNA was again subject to PCR amplification as described above for 14 cycles. The amplified product was used as input into PacBio SMRTbell library construction.

\section{PacBio library construction and sequencing}

Duplicate $2 \mathrm{~kb}$ PacBio SMRTbell libraries were prepared, each from $750 \mathrm{ng}$ un-fragmented, normalized cDNA, according to the DNA Template Prep kit 2.0 protocol (250 bp-3 kb) (Pacific Biosciences, Menlo Park, CA, USA, \#100-222-300). The PacBio library complex was mixed with DNA/Polymerase binding kit P4 (4.5:1,v:v) (Pacific Biosciences, Menlo Park, CA, USA, \#100-236-500) to obtain an on-plate concentration of $0.225 \mathrm{nM}$. Samples were sequenced at Washington University's HHMI-designated Pacific Biosciences (PacBio) sequencing site, which is equipped with RSII technology, capable of generating an average of 4-6 Kb read length with 3-20 Kb library preparations, generating about $1200 \mathrm{Mb}$ per SMRT cell. The library complex was sequenced with four SMRT cells at 75min collection protocol (Standard Seq v3) and C2 sequencing chemistry, producing 192,888 CCSs.

\section{Genome sequencing and assembly}

The A. ceylanicum whole genome shotgun libraries with $3 \mathrm{~kb}$ and $8 \mathrm{~kb}$ inserts were prepared and sequenced on the Roche/454 platform, followed by Newbler assembly, as previously described $[2,35]$. The initial assembly was further improved using our in-house tools CIGA (Cdna tool for Improving Genome Assembly) and PyGap (gap closure tool) by incorporating 1.56 million 454 cDNA reads from the closely-related hookworm A. caninum [36] that linked different assembly contigs. The Pyramid assembler (packaged in PyGap) was then used to align Illumina genomic paired-end reads to extend contigs and close gaps.

\section{Gene calling, annotation and comparison}

Repeat sequences were identified by generating a custom repeat library using Repeatmodeler (http://www.repeatmasker.org/RepeatModeler/). The ribosomal RNA genes were 
identified using RNAmmer [37] and transfer RNAs (tRNAs) were identified using tRNAscan-SE [38]. Other non-coding RNAs (such as microRNAs) were identified by a sequence homology search of the Rfam database [39]. These repeats and predicted RNAs were then masked using RepeatMasker [40]. Protein-coding genes were predicted using a combination of ab initio predictors Snap [41] and Fgenesh [42] and the evidence based predictor Augustus [43]. These predictions were fed to the annotation pipeline tool Maker (version 2.26) [44] which utilizes aligned EST [20] and protein evidence, to revise the predicted gene structures. A consensus gene set from the above prediction algorithms was generated, using a logical, hierarchical approach developed at The McDonnell Genome Institute [1]. In summary, Quality Index (QI) values produced by Maker were evaluated to produce a high confidence gene set, by retaining gene predictions containing (a) splice sites confirmed by an EST or exons that overlap an EST, or (b) exons that overlap multiple ESTs or protein alignments were retained. The remaining genes were retained as part of the final gene set if they met at least one of the following criteria: (i) A significant BLAST against Swissprot [45] $(\mathrm{E}<1 \mathrm{e}-6)$; (ii) A significant RPSBLAST against Pfam [46] $(\mathrm{E}<1 \mathrm{e}-3)$; (iii) A significant RPSBLAST against $\mathrm{CDD}$ [47] $(\mathrm{E}<1 \mathrm{e}-3$ and coverage $>40 \%)$ or (iv) A significant similarity-based search against GenesDB from KEGG [26, 48], ( $\geq 55 \%$ identity and $\geq 35$ bit score). No genes with $>10 \%$ overlap were retained in the final gene set, and limited manual review was performed to confirm the core gene set used to evaluate completeness (CEGMA $[49,50])$. This process was repeated utilizing the PacBio reads as evidence during the Maker gene annotation.

Functional annotations of the deduced proteins were determined using a BLAST search against the KEGG database $[26,48]$ to assign enzyme-based biological pathways annotations. Gene product naming was determined by BER (JCVI: http://ber.sourceforge.net).

\section{Illumina RNA-seq library construction, sequencing, and processing}

Non-normalized cDNA from a 16-day adult male wholeworm A. ceylanicum sample was used to construct Multiplexed Illumina paired end small fragment libraries according to the manufacturer's recommendations (Illumina Inc., San Diego, CA; as previously described [1]) with the following exceptions: 1) $500 \mathrm{ng}$ of cDNA was sheared using a Covaris S220 DNA Sonicator (Covaris, INC. Woburn, MA) to a size range between 200 and 400 bp. 2) Four PCR reactions were amplified to enrich for proper adaptor ligated fragments and properly index the libraries. 3) The final size selection of the library was achieved by an AMPure paramagnetic bead (Agencourt, Beckman Coulter Genomics \#A63882, Beverly, MA) cleanup targeting 300-500 bp. The concentration of the library was accurately determined through qPCR according to the manufacturer's protocol (Kapa Biosystems, Inc., Woburn, MA) to produce a cluster count appropriate for the Illumina platform. The library was indexed and loaded along with 5 other libraries into two lanes of a HiSeq2000 version 3 flow cell. 2 X 101 bp read pairs (later clipped to $100 \mathrm{bp}$ using Consensus Assessment of Sequence and Variation [CASAVA, version 1.8]) were generated for the sample, producing 84,215,192 reads. 16-day adult males were used because based on available RNA-Seq datasets, they provide, on average, the most expressed genes with the highest coverage.

Analytical processing of the Illumina 100 bp reads began by using DUST to filter out regions of low compositional complexity and to convert them into Ns [51]. An in-house Perl script was used to remove Ns, which discards reads without at least 60 bases on non-N sequence. Sequences from host (pig genome; Sscrofa9.2, GCA_000003025.2 from GenBank [52]), bacteria (GBBCT from GenBank [52]), were screened. The resulting 42,107,596 cleaned RNA-Seq reads were mapped to the assembled $A$. ceylanicum genome using Tophat [53] (version 1.3.1), and calculating depth and breadth of coverage using Refcov (version 0.3, http://gmt.genome.wustl.edu/packages/ refcov/install.html). The number of reads associated with each gene was determined using HTSeq-Count [54], for each of the annotations. The same mapping and counting process was used to quantify mapping rates to the previously published $A$. ceylanicum genome [31].

The StringTie de novo transcriptome assembly tool [55] was used to assemble the same Illumina RNASeq reads into 14,611 StringTie contigs (assembled Illumina transcripts), which were then aligned to the A. ceylanicum genome assembly using HISAT [56]. The overlap of both individual mapped Illumina reads and assembled Illumina transcripts with the annotated predicted gene sets was calculated with custom PERL scripts.

\section{Additional files}

Additional file 1: Figure demonstrating the differences in UTR lengths between AC-Orig and AC-PB for (A) 3' UTRs and (B) 5' UTRs. (TIFF 493 kb)

Additional file 2: Table of KEGG annotations for AC-Orig and AC-PB. (XLSX 1706 kb)

\section{Abbreviations}

CCS: Circular consensus sequence; PacBio: Pacific Biosciences; SMRT: Singlemolecule real-time; UTR: Untranslated region; ZMWs: Zero-mode waveguides

Acknowledgements

We would like to thank Young-Jun Choi for running StringTie the outcome of which was used to compare assembled Illumina transcripts with AC-Orig and AC-PB annotations. 


\section{Funding}

This study was supported by funding of NIH-NHGRI U54HG003079 to R.K.W, and NIH-NIAID R01AI081803 and NIH-NIGMS R01GM097435 to M.M. The funding body had no role in the design of the study, collection, analysis, and interpretation of data, or in writing the manuscript.

\section{Availability of data and materials}

The datasets supporting the conclusions of this article are included within the article (and its additional files). The AC-PB annotated genes are deposited into Nematode.net at: http://nematode.net/Data/aceylanicum_PRJNA72583_annotations/Acey_pacbio_based_annotations.gff (PacBio improved annotation) and http://nematode.net/Data/aceylanicum_PRJNA72583_annotations/Acey_non_pacbio_annotations.gff (original annotation). The PacBio reads are deposited in NCBI Short Reads Archive, BioSample ID SAMN07451676.

\section{Authors' contributions}

M.M., RKW, and V.M. conceived and designed the study. JH conducted the experimental infections, collection of material, extraction of RNA for both PacBio and Illumina sequencing and interpretation of the functional annotations of the novel genes. SM and VM conducted PacBio experiments, $X G, B A R, X Z, K P$, and JM, conducted all analyses. $V M, X G, B A R$, and $M M$. wrote the manuscript. All the authors read and approved the final manuscript.

\section{Ethics approval and consent to participate}

An Indian strain of A. ceylanicum (US National Parasite Collection No. 102954) was maintained in Syrian hamsters (Mesocricetus auratus) obtained from commercial sources (Harlan labs, Envigo). Animals were housed and treated in strict accordance with the recommendations in the Guide for the Care and Use of Laboratory Animals of the National Institutes of Health, under protocols approved by the George Washington University Institutional Animal Care and Use Committee (protocols A147, A270).

\section{Consent for publication}

\section{Not applicable}

\section{Competing interests}

The authors declare that they have no competing interests.

\section{Author details}

'McDonnell Genome Institute, Washington University School of Medicine, St Louis, MO 63108, USA. ²Department of Microbiology, Immunology and Tropical Medicine, The George Washington University, Washington DC 20037, USA. ${ }^{3}$ Department of Medicine, Washington University School of Medicine, St. Louis, MO 63110, USA.

\section{Received: 9 August 2017 Accepted: 19 February 2018}

\section{Published online: 01 March 2018}

\section{References}

1. Tang YT, Gao X, Rosa BA, Abubucker S, Hallsworth-Pepin K, Martin J, Tyagi R, Heizer E, Zhang X, Bhonagiri-Palsikar V, et al. Genome of the human hookworm Necator Americanus. Nat Genet. 2014;46:261-9.

2. McNulty SN, Strube C, Rosa BA, Martin JC, Tyagi R, Choi YJ, Wang Q, Hallsworth Pepin K, Zhang X, Ozersky P, et al. Dictyocaulus Viviparus genome, variome and transcriptome elucidate lungworm biology and support future intervention. Sci Rep. 2016;6:20316.

3. Mitreva M, Jasmer DP, Zarlenga DS, Wang Z, Abubucker S, Martin J, Taylor CM, Yin Y, Fulton L, Minx P, et al. The draft genome of the parasitic nematode Trichinella spiralis. Nat Genet. 2011;43:228-35.

4. Crompton DW. The public health importance of hookworm disease. Parasitology. 2000;121(Suppl):S39-50.

5. Bethony J, Brooker S, Albonico M, Geiger SM, Loukas A, Diemert D, Hotez PJ. Soil-transmitted helminth infections: ascariasis, trichuriasis, and hookworm. Lancet. 2006;367:1521-32.

6. Brooker S, Kabatereine NB, Tukahebwa EM, Kazibwe F. Spatial analysis of the distribution of intestinal nematode infections in Uganda. Epidemiol Infect. 2004;132:1065-71.

7. Traub RJ, Inpankaew T, Sutthikornchai C, Sukthana Y, Thompson RC. PCR-based coprodiagnostic tools reveal dogs as reservoirs of zoonotic ancylostomiasis caused by Ancylostoma ceylanicum in temple communities in Bangkok. Vet Parasitol. 2008;155:67-73.

8. Jiraanankul V, Aphijirawat W, Mungthin M, Khositnithikul R, Rangsin R, Traub RJ, Piyaraj P, Naaglor T, Taamasri P, Leelayoova S. Incidence and risk factors of hookworm infection in a rural community of central Thailand. Am J Trop Med Hyg. 2011;84:594-8.

9. Conlan JV, Khamlome B, Vongxay K, Elliot A, Pallant L, Sripa B, Blacksell SD, Fenwick S, Thompson RC. Soil-transmitted helminthiasis in Laos: a community-wide cross-sectional study of humans and dogs in a mass drug administration environment. Am J Trop Med Hyg. 2012;86:624-34.

10. Ngui R, Lim YA, Traub R, Mahmud R, Mistam MS. Epidemiological and genetic data supporting the transmission of Ancylostoma ceylanicum among human and domestic animals. PLoS Negl Trop Dis. 2012;6:e1522.

11. Ray DK, Bhopale KK. Complete development of ancylostoma ceylanicum (Looss, 1911) in golden hamsters, mesocricetus auratus. Experientia. 1972;28: 359-61

12. Menon S, Bhopale MK. Ancylostoma ceylanicum (Looss, 1911) in golden hamsters (Mesocricetus Auratus): pathogenicity and humoral immune response to a primary infection. J Helminthol. 1985;59:143-6.

13. Garside P, Behnke JM. Ancylostoma ceylanicum in the hamster: observations on the host-parasite relationship during primary infection. Parasitology. 1989;98(Pt 2):283-9.

14. Garside P, Behnke JM, Rose RA. Acquired immunity to Ancylostoma ceylanicum in hamsters. Parasite Immunol. 1990;12:247-58.

15. Behnke IM, Guest J, Rose R. Expression of acquired immunity to the hookworm Ancylostoma ceylanicum in hamsters. Parasite Immunol. 1997;19:309-18.

16. Khan AM, Gupta S, Katiyar JC, Srivastava VK. Correlation between degree of protection and humoral antibody response in hamsters immunized with somatic and excretory secretory antigens of Ancylostoma ceylanicum. Indian J Exp Biol. 1996;34:1015-8.

17. Ghosh K, Wu W, Antoine AD, Bottazzi ME, Valenzuela JG, Hotez PJ, Mendez $\mathrm{S}$. The impact of concurrent and treated Ancylostoma ceylanicum hookworm infections on the immunogenicity of a recombinant hookworm vaccine in hamsters. J Infect Dis. 2006;193:155-62.

18. Tritten L, Nwosu U, Vargas M, Keiser J. In vitro and in vivo efficacy of tribendimidine and its metabolites alone and in combination against the hookworms Heligmosomoides bakeri and Ancylostoma ceylanicum. Acta Trop. 2012;122:101-7.

19. Hu Y, Ellis BL, Yiu YY, Miller MM, Urban JF, Shi LZ, Aroian RV. An extensive comparison of the effect of anthelmintic classes on diverse nematodes. PLoS One. 2013;8:e70702.

20. Mitreva M, McCarter JP, Arasu P, Hawdon J, Martin J, Dante M, Wylie T, Xu J, Stajich JE, Kapulkin W, et al. Investigating hookworm genomes by comparative analysis of two Ancylostoma species. BMC Genomics. 2005;6:58.

21. Shagin DA, Lukyanov KA, Vagner LL, Matz MV. Regulation of average length of complex PCR product. Nucleic Acids Res. 1999;27:e23.

22. Gao X, Frank D, Hawdon JM. Molecular cloning and DNA binding characterization of DAF-16 orthologs from Ancylostoma hookworms. Int J Parasitol. 2009:39:407-15.

23. Cappello M, Hawdon JM, Jones BF, Kennedy WP, Hotez PJ. Ancylostoma caninum anticoagulant peptide: cloning by PCR and expression of soluble, active protein in E. Coli. Mol Biochem Parasitol. 1996;80:113-7.

24. Proudfoot NJ. Ending the message: poly(a) signals then and now. Genes Dev. 2011;25:1770-82.

25. Beaudoing E, Freier S, Wyatt JR, Claverie JM, Gautheret D. Patterns of variant polyadenylation signal usage in human genes. Genome Res. 2000;10:1001-10.

26. Kanehisa M, Goto S, Sato Y, Kawashima M, Furumichi M, Tanabe M. Data, information, knowledge and principle: back to metabolism in KEGG. Nucleic Acids Res. 2014;42:7

27. Hofmann J, El Ashry AEN, Anwar S, Erban A, Kopka J, Grundler F. Metabolic profiling reveals local and systemic responses of host plants to nematode parasitism. Plant J. 2010;62:1058-71.

28. Singh S, Orr D, Divinagracia E, McGraw J, Dorff K, Forst S. Role of secondary metabolites in establishment of the mutualistic partnership between Xenorhabdus nematophila and the Entomopathogenic nematode Steinernema Carpocapsae. Appl Environ Microbiol. 2015;81:754-64

29. Tobias NJ, Heinrich AK, Eresmann H, Wright PR, Neubacher N, Backofen R, Bode HB. Photorhabdus-nematode symbiosis is dependent on hfq-mediated regulation of secondary metabolites. Environ Microbiol. 2017;19:119-29.

30. Banton MC, Tunnacliffe A. MAPK phosphorylation is implicated in the adaptation to desiccation stress in nematodes. J Exp Biol. 2012;215:4288. 
31. Schwarz EM, Hu Y, Antoshechkin I, Miller MM, Sternberg PW, Aroian RV. The genome and transcriptome of the zoonotic hookworm Ancylostoma ceylanicum identify infection-specific gene families. Nat Genet. 2015;47:416-22.

32. Barrett LW, Fletcher S, Wilton SD. Regulation of eukaryotic gene expression by the untranslated gene regions and other non-coding elements. Cell Mol Life Sci. 2012;69:3613-34.

33. Bull RA, Eltahla AA, Rodrigo C, Koekkoek SM, Walker M, Pirozyan MR, Betz-Stablein B, Toepfer A, Laird M, Oh S, et al. A method for near full-length amplification and sequencing for six hepatitis $C$ virus genotypes. BMC Genomics. 2016;17:247.

34. Hawdon J, GA S. Long term storage of hookworm infective larvae in buffered saline solution maintains larval responsiveness to host signals. J Helminthol Soc Wash. 1991;58:140-2.

35. Tyagi R, Joachim A, Ruttkowski B, Rosa BA, Martin JC, Hallsworth-Pepin K, Zhang X, Ozersky P, Wilson RK, Ranganathan S, et al. Cracking the nodule worm code advances knowledge of parasite biology and biotechnology to tackle major diseases of livestock. Biotechnol Adv. 2015;33:980-91.

36. Wang Z, Abubucker S, Martin J, Wilson RK, Hawdon J, Mitreva M. Characterizing Ancylostoma caninum transcriptome and exploring nematode parasitic adaptation. BMC Genomics. 2010;11:307.

37. Lagesen $\mathrm{K}$, Hallin $\mathrm{P}$, Rodland EA, Staerfeldt HH, Rognes T, Ussery DW. RNAmmer: consistent and rapid annotation of ribosomal RNA genes. Nucleic Acids Res. 2007;35:3100-8.

38. Lowe TM, Eddy SR. tRNAscan-SE: a program for improved detection of transfer RNA genes in genomic sequence. Nucleic Acids Res. 1997;25:955-64.

39. Griffiths-Jones S, Bateman A, Marshall M, Khanna A, Eddy SR. Rfam: an RNA family database. Nucleic Acids Res. 2003;31:439-41.

40. Tarailo-Graovac M, Chen N. Using RepeatMasker to Identify Repetitive Elements in Genomic Sequences. In: Current Protocols in Bioinformatics. Wiley; 2002

41. Korf I. Gene finding in novel genomes. BMC Bioinformatics. 2004:5:59.

42. Salamov AA, Solovyev W. Ab initio gene finding in drosophila genomic DNA. Genome Res. 2000:10:516-22.

43. Stanke M, Keller O, Gunduz I, Hayes A, Waack S, Morgenstern B. AUGUSTUS: ab initio prediction of alternative transcripts. Nucleic Acids Res. 2006:34: W435-9.

44. Cantarel BL, Korf I, Robb SM, Parra G, Ross E, Moore B, Holt C, Sanchez Alvarado A, Yandell M. MAKER: an easy-to-use annotation pipeline designed for emerging model organism genomes. Genome Res. 2008;18:188-96.

45. Boutet E, Lieberherr D, Tognolli M, Schneider M, Bairoch A. UniProtKB/SwissProt. Methods Mol Biol. 2007;406:89-112.

46. Finn RD, Bateman A, Clements J, Coggill P, Eberhardt RY, Eddy SR, Heger A, Hetherington K, Holm L, Mistry J, et al. Pfam: the protein families database. Nucleic Acids Res. 2014:42:D222-30.

47. Marchler-Bauer A, Derbyshire MK, Gonzales NR, Lu S, Chitsaz F, Geer LY, Geer RC, He J, Gwadz M, Hurwitz DI, et al. CDD: NCBI's conserved domain database. Nucleic Acids Res. 2015;43:D222-6.

48. Kanehisa M, Goto S. KEGG: kyoto encyclopedia of genes and genomes. Nucleic Acids Res. 2000;28:27-30.

49. Parra G, Bradnam K, Korf I. CEGMA: a pipeline to accurately annotate core genes in eukaryotic genomes. Bioinformatics. 2007;23:1061-7.

50. Parra G, Bradnam K, Ning Z, Keane T, Korf I. Assessing the gene space in draft genomes. Nucleic Acids Res. 2009;37:289-97.

51. Morgulis A, Gertz EM, Schaffer AA, Agarwala R. A fast and symmetric DUST implementation to mask low-complexity DNA sequences. J Comput Biol. 2006;13:1028-40.

52. Benson DA, Karsch-Mizrachi I, Lipman DJ, Ostell J, Wheeler DL. GenBank. Nucleic Acids Res. 2005;33:D34-8

53. Trapnell C, Pachter L, Salzberg SL. TopHat: discovering splice junctions with RNA-Seq. Bioinformatics. 2009;25:1105-11.

54. Anders S, Pyl TP, Huber W. HTSeq - a python framework to work with high-throughput sequencing data. Bioinformatics. 2015;31(2):166-9.

55. Pertea M, Pertea GM, Antonescu CM, Chang T-C, Mendell JT, Salzberg SL. StringTie enables improved reconstruction of a transcriptome from RNA-seq reads. Nat Biotechnol. 2015;33:290.

56. Martin J, Rosa BA, Ozersky P, Hallsworth-Pepin K, Zhang X, Bhonagiri-Palsikar V, Tyagi R, Wang Q, Choi YJ, Gao X, McNulty SN, Brindley PJ, Mitreva M. Helminth.net: expansions to Nematode.net and an introduction to Trematode.net. Nucleic Acids Res. 2015;43(D1):D698-D706.

\section{Submit your next manuscript to BioMed Central and we will help you at every step:}

- We accept pre-submission inquiries

- Our selector tool helps you to find the most relevant journal

- We provide round the clock customer support

- Convenient online submission

- Thorough peer review

- Inclusion in PubMed and all major indexing services

- Maximum visibility for your research

Submit your manuscript at www.biomedcentral.com/submit
Biomed Central 